Article

\title{
Investigation on Moisture Damage Prevention of a Spherical Hinge Structure of a Swivel Bridge
}

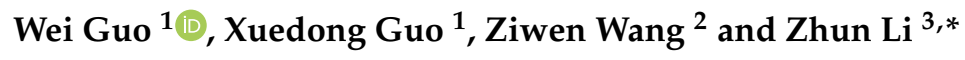 \\ 1 School of Transportation, Jilin University, Changchun 130022, China; guowei17@mails.jlu.edu.cn (W.G.); \\ guoxd@jlu.edu.cn (X.G.) \\ 2 Changji Intercity Railway Co., Ltd., Changchun 130021, China; wangziwen7007@163.com \\ 3 The Key Laboratory of Road and Traffic Engineering, Ministry of Education, Tongji University, \\ Shanghai 201804, China \\ * Correspondence: guoweijlu@outlook.com; Tel.: +86-0516-85095446
}

Received: 11 September 2020; Accepted: 1 October 2020; Published: 3 October 2020

\begin{abstract}
As a key component of a swivel bridge, the spherical hinge is a steel-concrete structure, which is susceptible to moisture damage during waiting time. In this paper, spherical hinge moisture damage prevention is investigated comprehensively from two aspects of impermeable concrete and steel-concrete interface waterproof coating. Three impermeable concretes were prepared and tested by the compressive strength test, splitting tensile test, four-point bending test and the impermeability test. The test results illustrated that addition of cementitious capillary crystalline active masterbatch (CCCAM) and polypropylene fiber (PP) could improve the toughness and brittleness of concrete. The addition of CCCAM was an effective technique for improving the permeability of concrete. However, the incorporation of PP and CCCAM at the same time cannot improve the impermeability of concrete. This may be because the chaotic support structure formed by PP prevents the infiltration and uniform dispersion of CCCAM. A waterproof coating consolidation performance test was proposed to quantify the interface bond strength of waterproof coatings and assess the impact of temperature, moisture and freeze-thawing cycles on consolidation performance of waterproof coatings. The test results showed that temperature had a significant effect on the interface consolidation property of waterproof coatings and the optimal dosage of SBS modified asphalt (SBS), polyurethane (PLT) and unsaturated polyester resin (UPLS) waterproof coating is $1.18 \mathrm{~kg} / \mathrm{m}^{2}, 0.95 \mathrm{~kg} / \mathrm{m}^{2}$ and $1.15 \mathrm{~kg} / \mathrm{m}^{2}$, respectively. Moreover, it was found that PLS waterproof coating maintained excellent properties in complex environment. This is because PLS has excellent shear strength and rubber characteristics, and it can form a hard-soft-hard transition layer between the concrete and steel, reducing the impact of environmental factors.
\end{abstract}

Keywords: swivel bridge; spherical hinge structure; moisture damage; impermeable concrete; waterproof coating

\section{Introduction}

To ensure the construction safety of the new bridge across the existing railways and highways and reduce the interference to normal operation of the existing railways and highways, swivel construction technology has become the main method for the construction of over-line continuous beam bridges [1-3]. As a new bridge construction technology, swivel bridge construction can avoid unfavorable terrain and ensure that cross-line traffic is not interrupted compared to traditional bridge construction technology [4-6]. Swivel bridge construction technology is mainly composed of three major systems, namely the rotation support system, the balance system and the traction system $[7,8]$. The spherical hinge structure is the core component of the rotation support system, which not only 
plays the role of the bearing the weight of the superstructure, but also can be used as a balance system to adjust the posture of the bridge and control the eccentric distance of bridge [9]. The construction of a swivel bridge is shown in Figure 1.

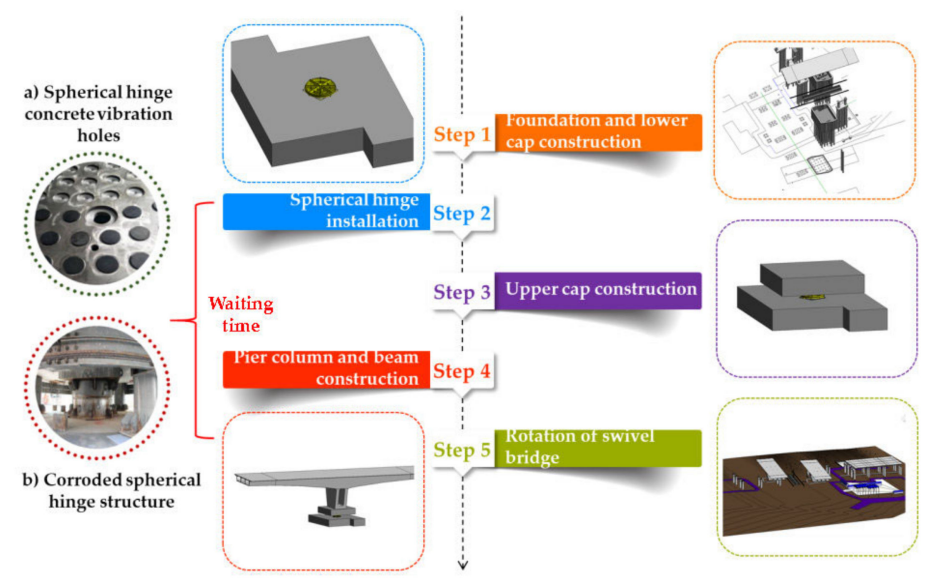

Figure 1. Construction process of the swivel process.

The construction period of a swivel bridge is relatively long. The construction of the beam and pier column needs to be carried out after the installation of the spherical hinge, so the swivel bridge does not start to rotate immediately, and the waiting time generally is several months or one or two years [10-12]. During the period of waiting time, there is generally water seepage in the foundation pit. Moreover, there are tiny gaps in the spherical hinge structure, such as concrete vibration holes, bolt connection holes and welding gaps. It is easy for moisture to penetrate into the spherical hinge system during the waiting time. The steel spherical hinge is made of a metal material, and the electrochemical reaction of the spherical hinge occurs with the moisture, which leads to metal corrosion.

Moisture damage such as corrosion of the spherical hinge increase the potential risk to the safety of the swivel bridge. To ensure that the swivel bridge rotates stably and accurately, it is necessary to develop a technology that can effectively control the moisture damage of spherical hinge during the waiting period. The research on moisture damage prevention can be carried out from two aspects of waterproof structure and waterproof material [13]. However, due to the unique structure of the spherical hinge, the waterproof structuring of a spherical hinge is difficult to realize. At present, impermeability concrete and waterproof coating of the concrete-spherical hinge interface are the effective technologies to prevent moisture damage to the spherical hinge. Impermeability concrete can improve the impermeability of concrete mainly by improving the density of the concrete, changing the pore structure of the concrete and blocking the seepage passage [14-17]. Zhang et al. found that fiber could improve water impermeability. The water absorption is almost halved when polypropylene fiber content is $0.6 \mathrm{~kg} / \mathrm{m}^{3}$ [18]. Guo et al. studied the permeability of superabsorbent polymer (SAP) modified concrete. The research showed that the addition of an appropriate amount of SAP could effectively improve the anti-permeability performance of concrete [19]. The waterproof coating is set between the spherical hinge and concrete, which can prevent the moisture from entering the spherical hinge to cause corrosion. Moreover, the waterproof coating can bond the spherical hinge and the concrete and coordinate the temperature shrinkage deformation of the spherical hinge and the concrete. Liu et al. found that waterborne epoxy resin emulsified asphalt had a strong waterproof performance on the bridge deck pavement as tack coat [20]. Rhee et al. delineated the relationship between the deterioration status of the concrete bridge deck and the asphalt concrete overlay, waterproof layer, cover thickness of rebar, corrosion of rebar, and chloride contents in the concrete. The results showed that deterioration of the concrete of the bridge deck was closely related to the functionality (performance) of the waterproof layer, and the deteriorated depth was significantly related to the average chloride content in the cover concrete of the top rebar [21]. 
As a key component of a swivel bridge, the spherical hinge is a steel-concrete structure, which is susceptible to moisture damage during the waiting time. In this paper, spherical hinge moisture damage prevention is investigated comprehensively from two aspects of impermeable concrete and steel-concrete interface waterproof coating. Three impermeable concretes were prepared and tested by the compressive strength test, splitting tensile test, four-point bending test and the impermeability test. Moreover, a waterproof coating consolidation performance test was proposed to quantify the interface bond strength of waterproof coatings and determine the optimal dosage of waterproof coatings. Then, the effect of temperature, moisture and freeze-thawing cycles on the consolidation performance of waterproof coatings was discussed to judge the waterproof coating with best performance.

\section{Materials and Sample Preparation}

\subsection{Cement}

'P.O42.5R' Ordinary Portland cement (JTG E30-2005, Table A1) acquired from North Cement Co., Ltd. (Siping, China) was used in this paper. The main technical parameters of 'P.O42.5R' Ordinary Portland cement are shown in Table A1.

\subsection{Aggregates}

In this study, crushed and sharp-edged aggregates (Jiutai, China) were used for preparation of impermeable concrete. Physical properties and the gradation of coarse aggregates are listed in Table A2 and Figure 2.

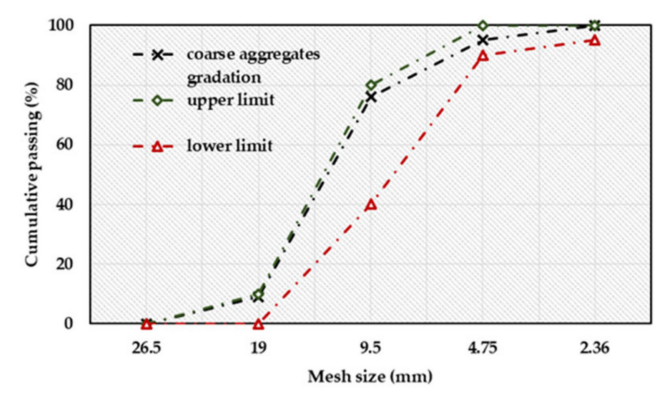

(a)

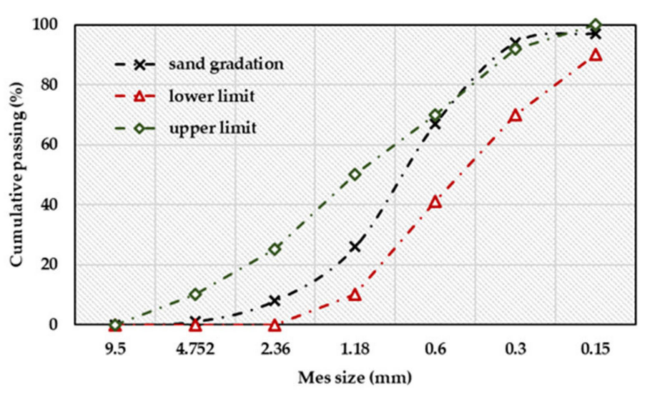

(b)

Figure 2. Gradation of coarse aggregates and sand. (a) Gradation of coarse aggregates; (b) gradation of sand

As the skeleton of the concrete, sand and stone are designated the skeleton. The role of sand in concrete is to adjust and optimize the proportion of the mixture. In this paper, Yinma river sand (Jiutai, China) was selected for the preparation of impermeable concrete. The Yinma river sand is a medium sand with a fineness modulus of 2.95 , and the sand ratio is $35 \%$. Physical properties and the gradation of the sand are listed in Table A3 and Figure 2. The physical properties and gradation of coarse aggregate and sand used in this paper meet the requirement of the specification for the mix proportion design of ordinary concrete (JGJ55-2011).

\subsection{Fly Ash}

Fly ash particles have a large specific surface area, which can effectively fill the microstructure of the aggregate. The addition of fly ash can improve the fluidity, cohesion and water retention of concrete mixtures, reduce temperature cracks and improve the durability of concrete. According to the "Specification for mix proportion design of ordinary concrete" (JGJ55-2011), F-class fly ash should be selected for impermeable concrete and the grade of fly ash should not be lower than II. Therefore, F-class and I-grade fly ash produced by Hengnuo filter material Co., Ltd. (Gongyi, China) was selected 
for further research, as is shown in Figure 3. The main technical parameters of fly ash are shown in Table A4.

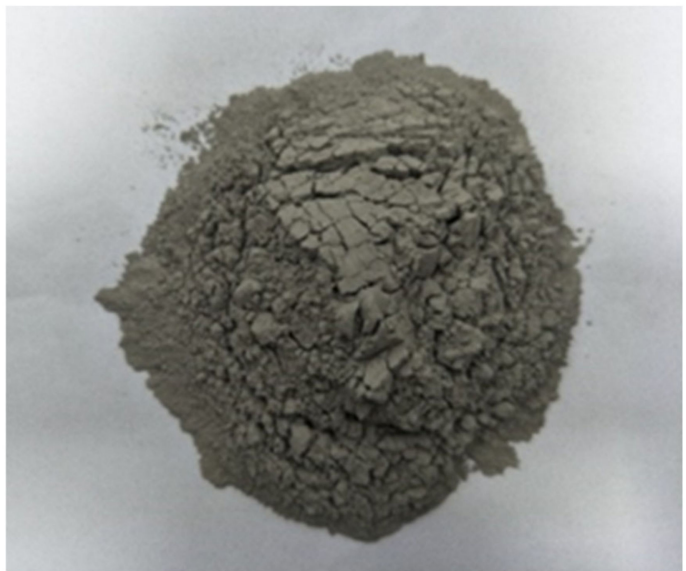

(a)

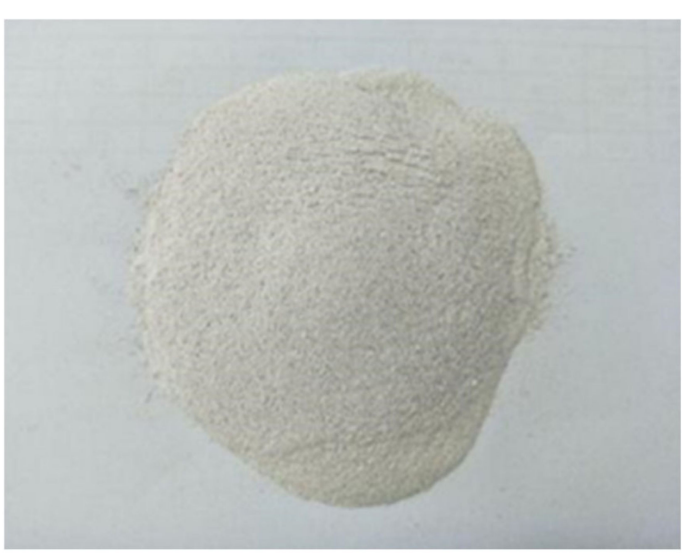

(c)

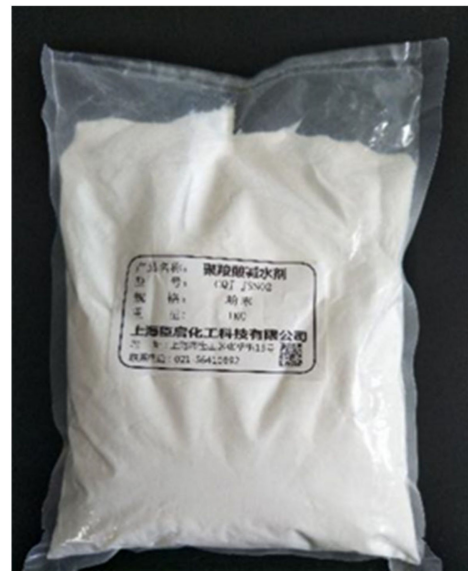

(b)

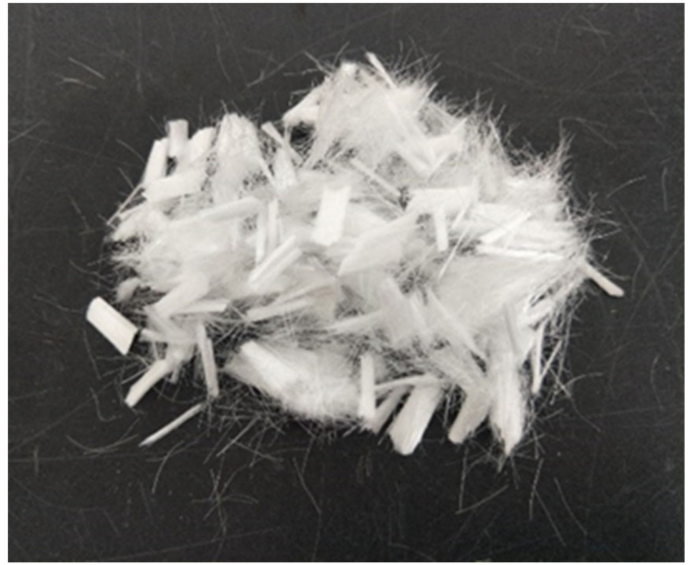

(d)

Figure 3. Main materials used in this paper. (a) Fly ash; (b) polycarboxylate superplasticizer; (c) cementitious capillary crystalline active masterbatch; (d) polypropylene fiber.

\subsection{Water-Reducing Agent}

In this paper, the water-cement ratio of the impermeable concrete containing fiber is relatively low, so a superplasticizer is need for adjusting the workability of the mixing concrete. Generally, the water reducing rate of the superplasticizer is $15 \%-30 \%$, which is two times higher than an ordinary water reducer. The greater the amount of superplasticizer, the better the water-reducing effect. However, when the amount of the water reducer exceeds a certain value, the effect is not obvious, nor economical. In general, the amount of superplasticizer is $0.1-0.5 \mathrm{wt} . \%$ of the gelling material, and the water reducing rate is generally more than $20 \%$. The superplasticizer selected in this article was a polycarboxylate superplasticizer, which produced by Chenqi chemical technology Co., Ltd. (Shanghai, China), as is shown in Figure 3. The amount of polycarboxylate superplasticizer is $0.2 \mathrm{wt} . \%$ of the gelling material.

\subsection{Impermeable Concrete Additive}

Cementitious capillary crystalline waterproofing (CCCW) material is a kind of rigid waterproof material which is composed of ordinary Portland cement, fine quartz sand (or silica sand) as the base material and mixed with active chemicals. Cementitious Capillary Crystalline Active Masterbatch (CCCAM) is the active ingredient from CCCW and can penetrate into the cement matrix through the carrier of moisture and react with hydration products to form crystalline or gelatinous substances which fill the capillary pores and micro cracks [22-24]. The main application of CCCW material 
is to improve the densification, impermeability, and self-healing capability of concrete structures. The CCCAM selected in this paper was a DMC-S-WS-710B impermeable concrete additive produced by DeMei Waterproof Material Co., Ltd. (Xi'an, China), as is shown in Figure 3. The main technical parameters of DMC-S-WS-710B CCCAM are shown in Table A5.

Polypropylene fiber (PP) is a crystalline polymer with low weight, high strength, excellent elasticity and corrosion resistance, etc. The addition of polypropylene fiber can form a random distribution network reinforcement system, which can effectively control the micro-cracks caused by plastic shrinkage of the concrete [25-27]. The polypropylene fiber produced by Tuochuangao Building Materials Co., Ltd. (Cangzhou, China) was selected in this paper for study, as is shown in Figure 3. The main technical parameters of polypropylene fiber are shown in Table A6.

\subsection{Waterproof of Coating Materials}

The waterproof coating materials are mainly applied on the contact interface between the spherical hinge and the concrete, which plays a significant role on the moisture issue of the spherical hinge system. If a consolidation failure occurs at the waterproof coating, the moisture will penetrate into the spherical hinge structure, which will cause the corrosion of the spherical hinge. In this paper, three representative waterproof coating materials were selected for study, which are Styrene-Butadiene-Styrene modified asphalt (SBS), polyurethane (PLT) and unsaturated polyester resin (UPLS). The SBS modified asphalt was acquired from Zibo Industry Co., Ltd. (Shandong, China), the technical parameters of SBS modified asphalt are shown in Table A7.

PLT is a new organic polymer material, and it has many excellent properties, such as good wear resistance, high mechanical strength, strong consolidation performance [28,29]. Moreover, PLT has excellent recovery properties, which can be used for dynamic seams. Based on the above advantages, PLT is widely used in waterproofing and leakage repair of roofs, toilets and exterior walls. The SINB polyurethane waterproof coating produced by Hanlong Industry Co., Ltd. (Shanghai, China) was selected for this research. The technical parameters of PLT are shown in Table A8.

UPLS is a generally linear polymer compound with ester bonds and unsaturated double bonds formed by condensation polymerization of unsaturated dibasic acid diols or saturated dibasic acids and diols. UPLS has excellent heat resistance, chemical corrosion resistance, dielectric properties and mechanical performance [30,31]. The mechanical performance includes high tensile strength, bending strength and compressive strength. The UPLS selected in this paper was 99-A high transparent crystal resin produced by Xiangtaihao Chemical Co., Ltd. (Guangdong, China), the main technical parameters of UPLS are shown in Tables A9 and A10.

\subsection{Impermeable Concrete Sample Preparation}

According to the previous study, C30 concrete is designed according to the "Specification for mix proportion design of ordinary concrete" (JGJ55-2011). The amount of fly ash and polycarboxylate superplasticizer is $18 \mathrm{wt} . \%$ and $0.2 \mathrm{wt} . \%$ of cement. In addition to normal concrete, three impermeable concretes were also prepared for study, namely concrete with polypropylene fiber (PC), concrete with Cementitious capillary crystalline active masterbatch (SC), concrete with PP and CCCAM (SPC). According to the previous study, the optimal amount of PP is $0.9 \mathrm{~kg} / \mathrm{m}^{3}$, the optimal amount of CCCAM is $2 \mathrm{wt} . \%$ of concrete. The mix proportion of the four concretes is shown in Table 1. To facilitate the discussion, the normal concrete is denoted as $\mathrm{C}$.

Table 1. The mix proportion of four concrete (Unit: $\left.\mathrm{kg} / \mathrm{m}^{3}\right)$.

\begin{tabular}{ccccccccc}
\hline Type & Coarse Aggregate & Sand & Cement & Fly Ash & Superplasticizer & Water & PP & CCCAM \\
\hline C & 1280 & 690 & 325 & 58.5 & 0.65 & 156 & N/A & N/A \\
PC & 1280 & 690 & 325 & 58.5 & 0.65 & 156 & 0.9 & N/A \\
SC & 1280 & 690 & 325 & 58.5 & 0.65 & 156 & N/A & 6.5 \\
SPC & 1280 & 690 & 325 & 58.5 & 0.65 & 156 & 0.9 & 6.5 \\
\hline
\end{tabular}




\section{Laboratory Test Method}

\subsection{Mechaincal and Imperious Properties Test of Impermeable Concrete Sample}

\subsubsection{Compressive Strength Test}

The cubic compressive strength is the most basic mechanical property of concrete, and it is an important index to evaluate the strength grade of concrete. The size of the compression test sample selected in this paper is $100 \mathrm{~mm} \times 100 \mathrm{~mm} \times 100 \mathrm{~mm}$, and the loading speed of the compression testing machine is $0.5 \mathrm{MPa} / \mathrm{s}$. In this paper, concrete specimens with 3, 7 and 28 days curing periods were tested through the compression testing machine (HST Co., Ltd., Jinan, China), as is shown in Figure 4.

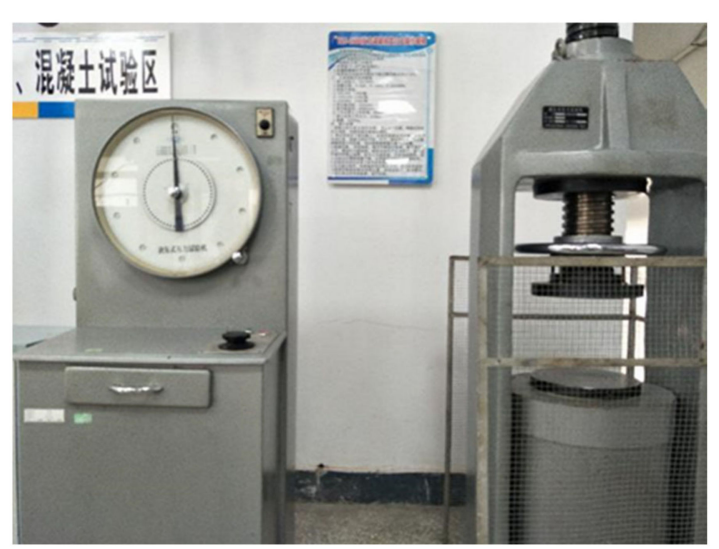

(a)

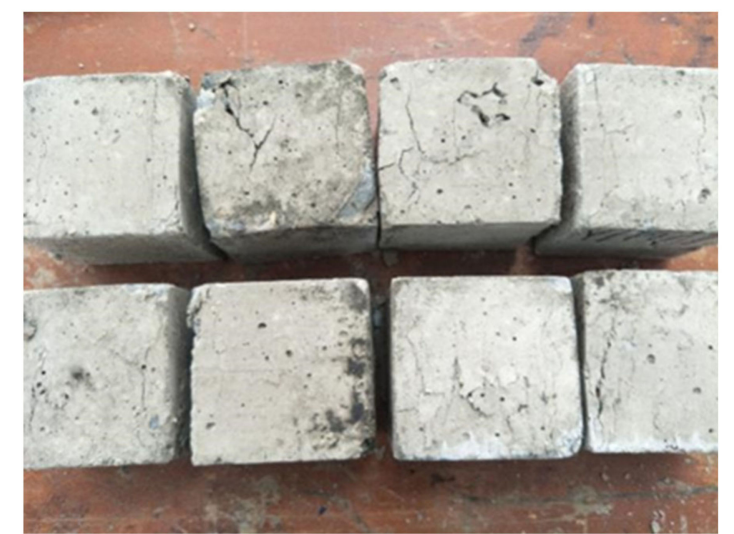

(b)

Figure 4. Compression testing machine and the damaged specimens after the test. (a) Compression testing machine; (b) damaged specimens after the compressive strength test.

\subsubsection{Splitting Tensile Test}

As a kind of brittle material, concrete will crack when it is under tension with a small deformation, and there is no residual deformation before it breaks. The splitting tensile strength of concrete is only $1 / 10-1 / 20$ of its compressive strength, and as the grade of concrete increases, the tension-compression ratio gradually decreases. Concrete does not generally rely on its splitting tensile strength during work, but splitting tensile strength is closely related to the cracking resistance. In structure design, splitting tensile strength is an important index to determine the cracking resistance of concrete, and sometimes it is also employed to indirectly evaluate the bonding strength of concrete and steel. In the splitting tensile test, the size of concrete specimens was $100 \mathrm{~mm} \times 100 \mathrm{~mm} \times 100 \mathrm{~mm}$, the loading speed was $0.05 \mathrm{MPa} / \mathrm{s}$. Concrete specimens with 3, 7 and 28 day curing periods were tested through the compression testing machine (HST Co., Ltd. Jinan, China), as is shown in Figure 5. It should be noticed that steel split strips and wooden pads are placed on the upper and lower surface of concrete specimen, and the direction of the wooden pads should be perpendicular to the top surface of specimen. The splitting tensile strength of concrete specimens can be calculated through the following formula.

$$
F_{S T}=\frac{2 F}{\pi A}=0.637 \frac{F}{A}
$$

where $F_{S T}$ is the splitting tensile strength of concrete specimens, $\mathrm{MPa} F$ is the failure load of specimens, $\mathrm{N}$; $A$ is split surface area of concrete specimen, $\mathrm{mm}$. 


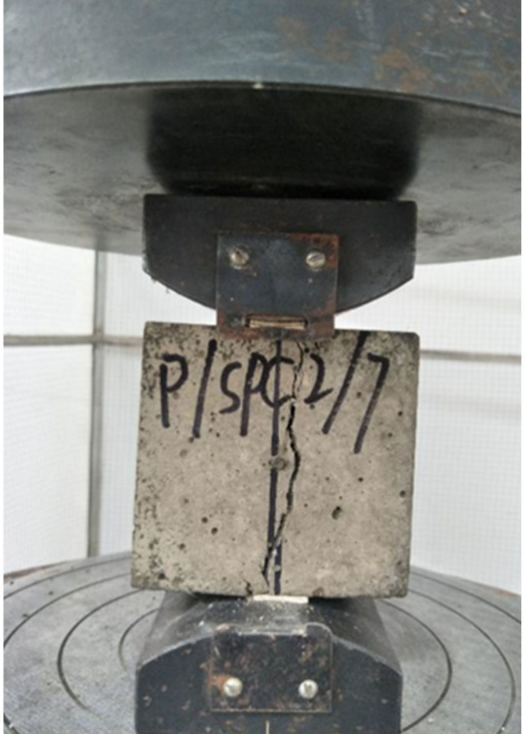

(a)

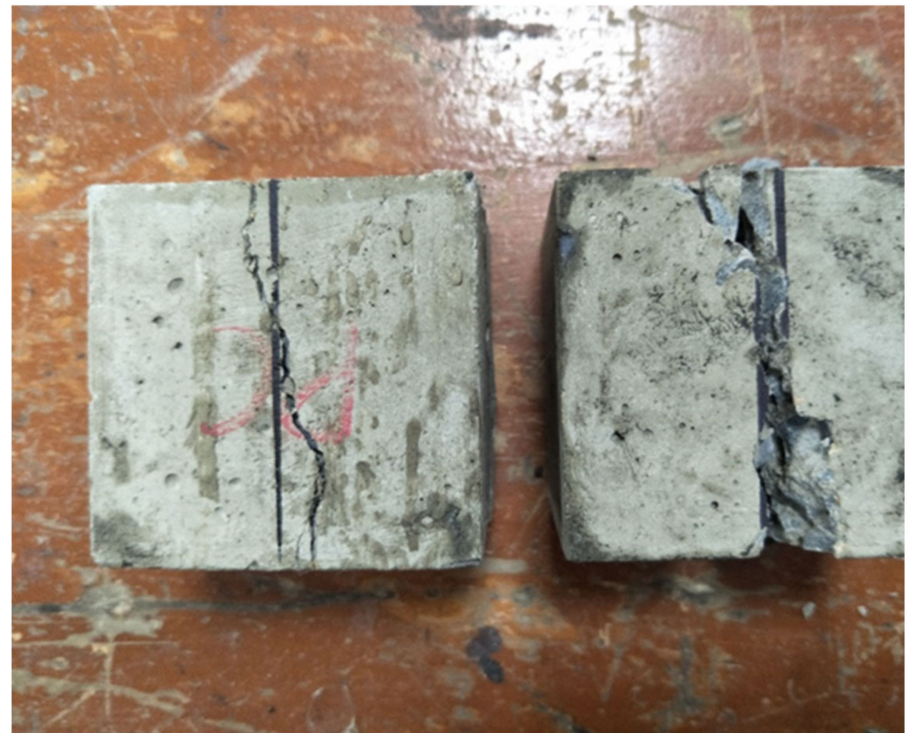

(b)

Figure 5. Splitting tensile test and the damaged specimens after the test. (a) Splitting tensile test; (b) damaged specimens after the splitting tensile test.

\subsubsection{Four-Point Bending Test}

Concrete is a brittle material, and the rupture strength is much lower than the compressive strength (about $1 / 6-1 / 10$ of the compressive strength). The rupture strength, as a key technical index has great significance in the application of impermeable concrete. The bending properties of impermeable concrete can be evaluated through the four-point bending test. In the four-point bending test, $100 \mathrm{~mm} \times 100 \mathrm{~mm} \times 400 \mathrm{~mm}$ prismatic specimens were prepared, and an electro-hydraulic servo universal testing machine (KNTEST Co., Ltd., Jinan, China) was employed, as is shown in Figure 6. Concrete specimens with $3 \mathrm{~d}, 7 \mathrm{~d}$ and $28 \mathrm{~d}$ curing periods were tested at a load speed of $0.08 \mathrm{MPa} / \mathrm{s}$, the damaged specimens after the test are shown in Figure 6.

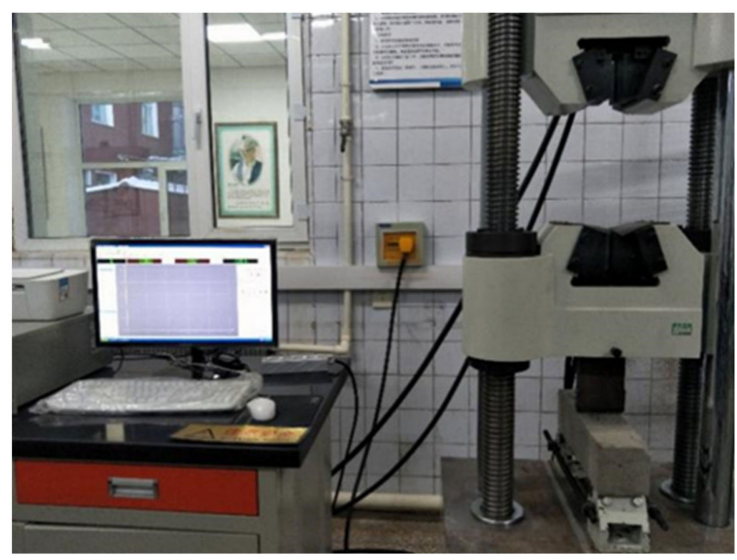

(a)

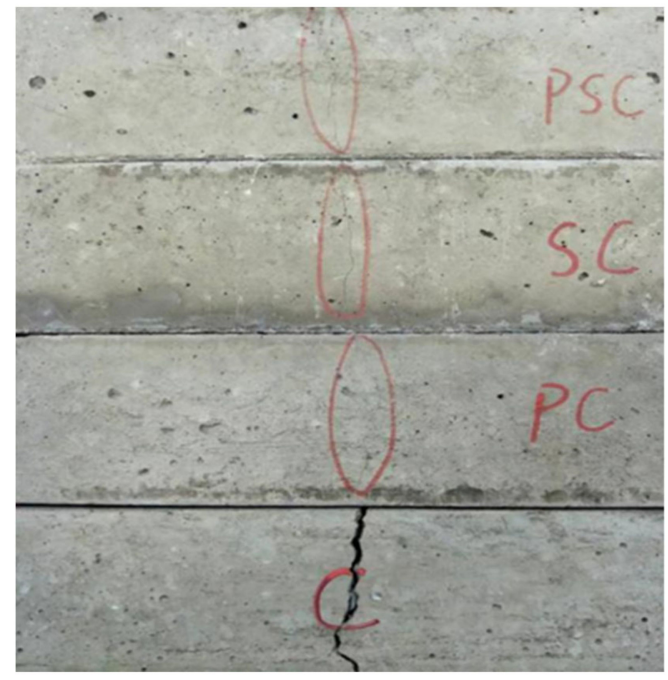

(b)

Figure 6. Electro-hydraulic servo universal testing machine and the damaged specimens after the four-point bending test. (a) Electro-hydraulic servo universal testing machine; (b) damaged specimens after four-point bending test. 
The rupture strength of concrete specimens can be calculated through the following formula.

$$
R_{f}=\frac{3 F L}{2 b h^{2}}
$$

where $R_{f}$ is the rupture strength of concrete specimens, MPa; $F$ is the failure load of specimens, N; $L$ is the distance between the supports, $\mathrm{mm} ; b$ is the cross-sectional width of specimens, $\mathrm{mm} ; h$ is the cross-sectional height of specimens, $\mathrm{mm}$.

\subsubsection{Impermeability Test}

The permeability of concrete refers to the penetration and migration of moisture, gases and ions in the concrete under the pressure of chemical and electric fields or physical forces. At present, the seepage method is the most commonly used method to test the impermeability of concrete. In this paper, an HP-4.0 seepage meter (CX, Co., Ltd., Jinan, China) is employed to evaluate the permeability of impermeable concrete. The test sample used in the impermeability test is a round table with a top diameter of $175 \mathrm{~mm}$, a lower bottom diameter of $185 \mathrm{~mm}$, and a height if $150 \mathrm{~mm}$, and every six specimens were a group. All the prepared concrete specimens need to be placed in the curing room for 28 days. According to the standard for test methods of long-term performance and durability of ordinary concrete (GB/T50082-2009), the water pressure applied by the seepage meter should be between 0.1 and $2.0 \mathrm{MPa}$. In this paper, the seepage height was applied in the impermeability test, and the water pressure was $1.0 \mathrm{MPa}$, the constant pressure time was $24 \mathrm{~h}$. After the test, the specimens were split, as is shown in Figure 7. In Figure 7, the water penetration height line is drawn with colored chalk, the part above the drawn line is a dry area, which has no water intrusion. Thus, the seepage height is measured and the relative permeability coefficient can be calculated as follows.

$$
S_{k}=\frac{m D_{m}^{2}}{2 T H}
$$

where $S_{k}$ is relative the permeability coefficient, $\mathrm{mm} / \mathrm{s} ; D_{m}$ is the average seepage height, $\mathrm{mm} ; H$ is the water pressure, which can be transformed into the height of water column, $\mathrm{mm}$. The height of water column corresponding to $1 \mathrm{MPa}$ water pressure was $1,020,000 \mathrm{~mm}$. $T$ is the constant pressure time, $\mathrm{s}$; $m$ is the water absorption rate of the concrete, the value in this paper was 0.03 .

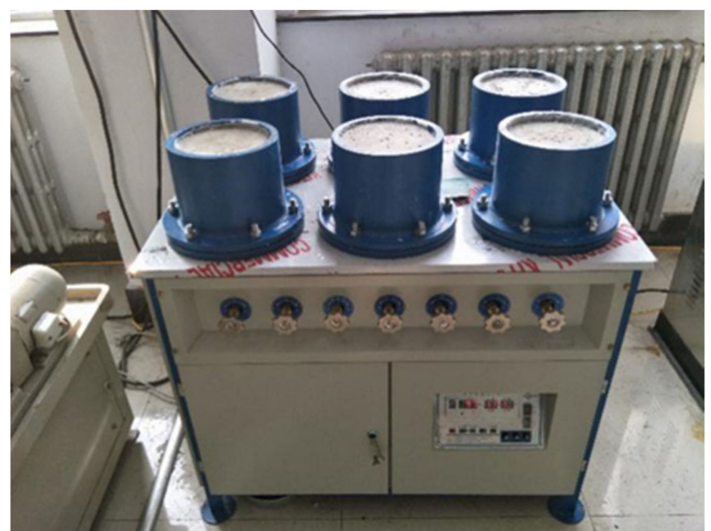

(a)

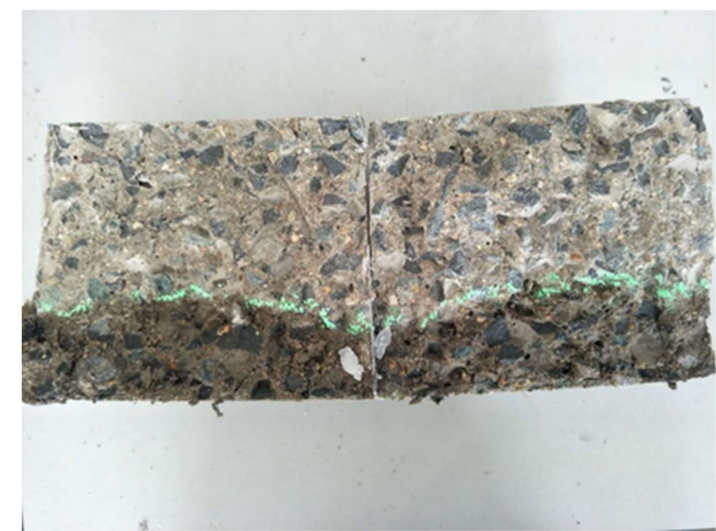

(b)

Figure 7. Concrete penetrometer and split specimen after the impermeability test. (a) Concrete penetrometer; (b) split specimen after the impermeability test.

\subsection{Consolidation Performance Test of Waterproof Coating}

At present, waterproof coating is generally employed for solving the corrosion issue of steel-concrete interface of the spherical hinge. The waterproof coating is applied on the contact 
surface between the concrete and the upper spherical hinge before the upper cap construction, so as to prevent the moisture infiltrating from the concrete into the rotation plane of the spherical hinge. However, the steel-concrete interface is a weak area of a swivel bridge, and its stress situation is complicated, which inevitably puts forward strict requirements on the consolidation performance of the waterproof coatings.

\subsubsection{Spherical Hinge Waterproof Coating Consolidation Strength Test Device}

To quantitatively study the consolidation performance of waterproof coating on the steel-concrete interface of the spherical hinge, a self-developed test device was employed for future study, as is shown in Figure 8.

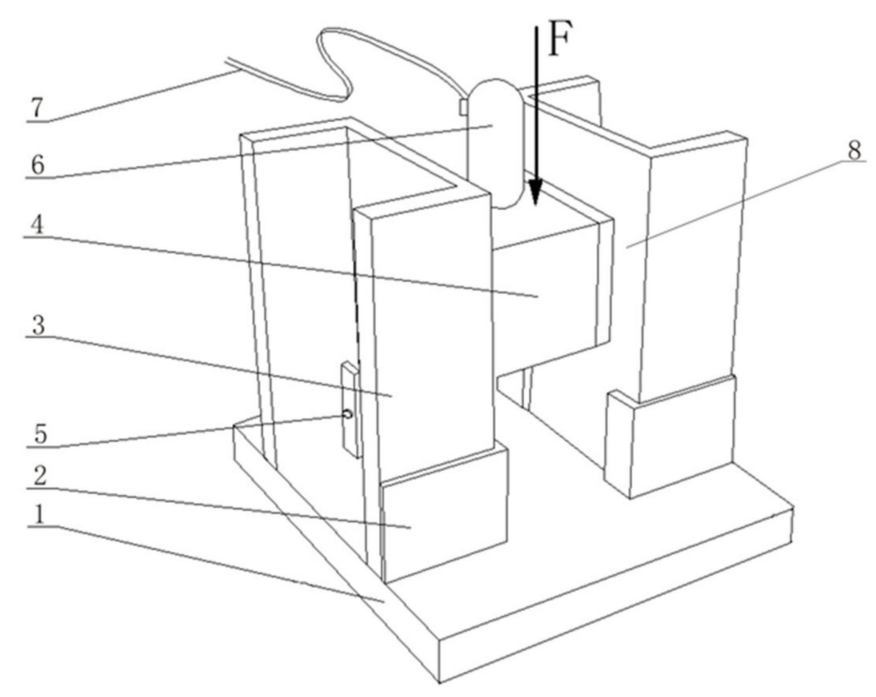

Figure 8. Spherical hinge waterproof coating consolidation strength test device. (1) Bottom plate; (2) positioning pieces; (3) steel splint; (4) concrete specimen; (5) positioning bolt; (6) indenter; (7) date transmission line; (8) waterproof coating.

The concrete specimen (5) is a standard cubic test block, and the size of the concrete specimen is $100 \mathrm{~mm} \times 100 \mathrm{~mm} \times 100 \mathrm{~mm}$. There are two positioning pieces (2) and steel splints (3) in the spherical hinge waterproof coating consolidation strength test device, and the two positioning plates (2) are fixed and installed on the bottom plate (1) in relative positions. The steel splints (3) are detachably fixed on the positioning pieces (2). The waterproof coating (8) is smeared on the center of the two steel splints (3), and the concrete specimen (4) is set between the two steel splints (3) and is attached to the waterproof coating (8). The data transmission line (7) and indenter (6), as part of the electronic universal testing machine are the monitoring and loading system. Moreover, the indenter (6) and the upper surface of the concrete specimen (4) are in smooth contact and in the middle. The self-developed spherical hinge waterproof coating consolidation strength test device has the advantages of simple structure, convenient installation and disassembly operation, etc. It can provide an approximate pure shear load on the waterproof coating between the steel-concrete interface. The consolidation strength of the waterproof coating between the steel-concrete interface can be accurately obtained.

\subsubsection{Consolidation Performance Test}

Based on the spherical hinge waterproof coating consolidation strength test device, the consolidation performance test is as follows.

- According to the above, standard cubic concrete specimens with a size of $100 \mathrm{~mm} \times 100 \mathrm{~mm} \times 100 \mathrm{~mm}$ are prepared and put in the curing room for 28 days under standard 
curing conditions. Then, the concrete specimens are removed from the curing room, and the two opposite faces of specimens are napped, respectively.

- The tested waterproof coating is smeared at the center of the two steel splints, and the coating area is consistent with the shape and size of the sides of concrete specimen, as is shown in Figure 9.

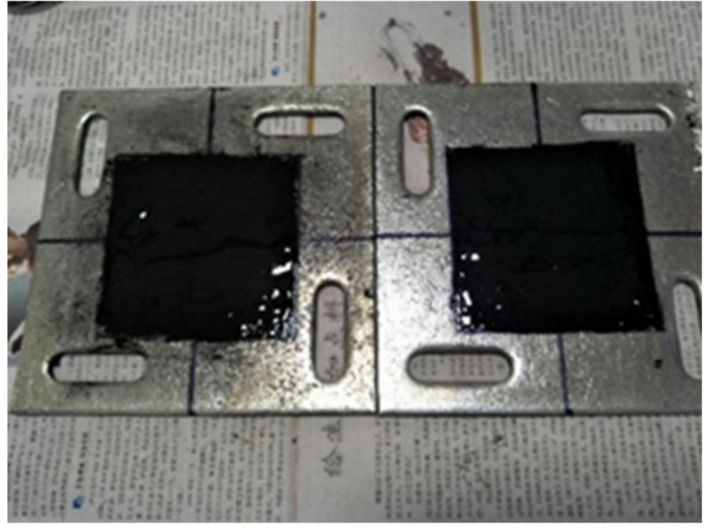

(a)

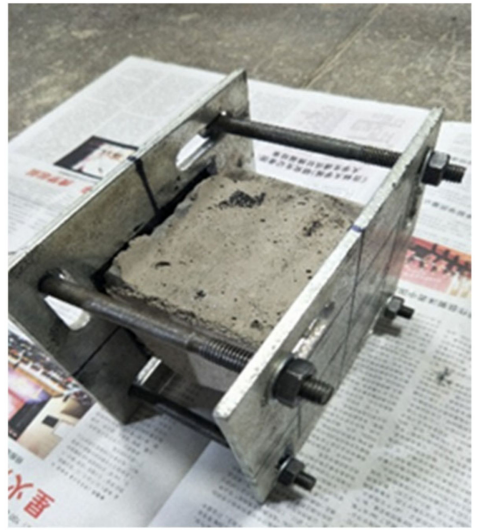

(b)

Figure 9. Concrete penetrometer and split specimen after the impermeability test. (a) Concrete penetrometer; (b) split specimen after the impermeability test.

- The two sides of the concrete specimen are laminated with the coating area of steel splints to form a 'hamburger' firm structure. Then, the four corners of the steel splints are connected through bolts to eliminate the influence of gravity on the concrete specimen, as is shown in Figure 9. Finally, the structure is fixed on the positioning sheet of the bottom plate.

- The assembled test specimen is placed in the electronic universal testing machine, and the position of the indenter is adjusted to ensure the indenter and the upper surface of the concrete specimen are in smooth contact and in the middle. Then, the electronic universal testing machine starts to perform the test until a shear failure occurs at the steel-concrete interface. After that, the test is stopped, and the failure load $F$ is recorded.

Based on the above test, the consolidation strength of waterproof coating can be obtained as follows.

$$
R_{c}=\frac{F}{2 a b}
$$

where $F$ is the is the failure load, $\mathrm{N} ; a$ is the length of the bonding surface of waterproof coating and concrete specimen, $\mathrm{mm} ; b$ is the width of the bonding surface of waterproof coating and concrete specimen, $\mathrm{mm}$.

\subsubsection{Analysis of Influencing Factors}

The consolidation performance of the waterproof coating between the spherical hinge and the concrete is affected by many factors, such as the type, dosage, temperature, moisture and freeze-thaw (F-T) cycles, etc. Therefore, considering the key factors in actual engineering, the consolidation performance of the above three types of waterproof coating were discussed from four aspects: waterproof coating dosage, temperature, moisture and F-T cycle. To determine the optimal dosage of the above three waterproof materials, and the dosage of the three waterproof materials was initially set as $0.6 \mathrm{~kg} / \mathrm{m}^{2}, 0.8 \mathrm{~kg} / \mathrm{m}^{2}, 1 \mathrm{~kg} / \mathrm{m}^{2}, 1.2 \mathrm{~kg} / \mathrm{m}^{2}$, respectively. In summer, both concrete and spherical hinges easily absorb heat, and the temperature of the waterproof coating can reach about $60^{\circ} \mathrm{C}$, while the temperature in the winter is relatively low. Therefore, the shear strength and deformation resistance of the waterproof coating are easily affected by the temperature. In this paper, the consolidation strength of waterproof coating is evaluated under the temperature conditions of $5{ }^{\circ} \mathrm{C}, 25^{\circ} \mathrm{C}, 40^{\circ} \mathrm{C}$ 
and $60^{\circ} \mathrm{C}$. The waterproof coating material needs to have excellent waterproof function. Therefore, the waterproof coating material needs to be able to ensure normal work under different humidity conditions. In this paper, the consolidation performance test is conducted at $25{ }^{\circ} \mathrm{C}$ and relative air humidity's of $30 \%, 60 \%, 95 \%$ and $100 \%$, respectively. In the seasonal frost region, the temperature changes in winter are particularly large. The volumes of the steel spherical hinge and surrounding concrete are large, and the contraction coefficients of steel and concrete material are also quite different. Thus, the waterproof coating needs to be able to coordinate the shear deformation between steel and concrete under such conditions, to prevent the moisture from entering the spherical hinge-concrete interface. In this paper, a freeze-thaw cycles test is adopted to evaluate the influence of F-T cycles on waterproof coating materials. The specimens were treated by vacuum saturation in $97.3 \mathrm{kPa}$ for $15 \mathrm{~min}$ and submerged in a container containing water, then the container with specimens was placed in the precision temp-enclosure at $-15^{\circ} \mathrm{C}$ and frozen for $12 \mathrm{~h}$. Then, the specimens were soaked in water at $15^{\circ} \mathrm{C}$ for $12 \mathrm{~h}$ through controlling the precision temp-enclosure. As described above, a complete freeze-thaw cycle was completed. After 5 freeze-thaw cycles, the damaged specimens were collected for the consolidation performance test.

\section{Results and Discussion}

\subsection{Compressive Strength Test Results}

The compressive strength of impermeable concrete samples is shown in Figure 10. As shown in Figure 10, for C, PC, SC and SPC, the compressive strength gradually increased with the increase of curing age and the compressive strength of four concretes meet the specifications. Under the same curing age, the sequence of compressive strength for impermeable concrete are SPC $>$ SC $>$ PC $>C$, respectively, which indicates that the addition of the cementitious capillary crystalline active masterbatch and polypropylene fiber can effectively increase the compressive strength of concrete. The incorporation of polypropylene fiber can fill the voids between the aggregates and compact the internal structure of concrete, thereby improving the compressive strength of concrete. However, the compressive and tensile strength of PP is relatively low, which makes the influence of PP on the compressive strength of concrete not significant. When the CCCAM is incorporated, hydration reaction and infiltrate crystallization by capillary action will occur in the concrete. The special active chemical substances in CCCAM play the role of catalysis and activation, it can react with the free ions in the concrete mortar to form water-insoluble crystalline substances. The crystallization can form rapidly and gradually fill the whole interior of the concrete. Moreover, the crystallization can enhance the interface bonding between the concrete and the aggregate, improve the internal microstructure of concrete, and compact the interior of the concrete, increase the compressive strength of concrete. The compressive strength of SPC is higher than that of PC and SC, indicating that the addition of CCCAM and PP improve the compressive strength of concrete better than them.

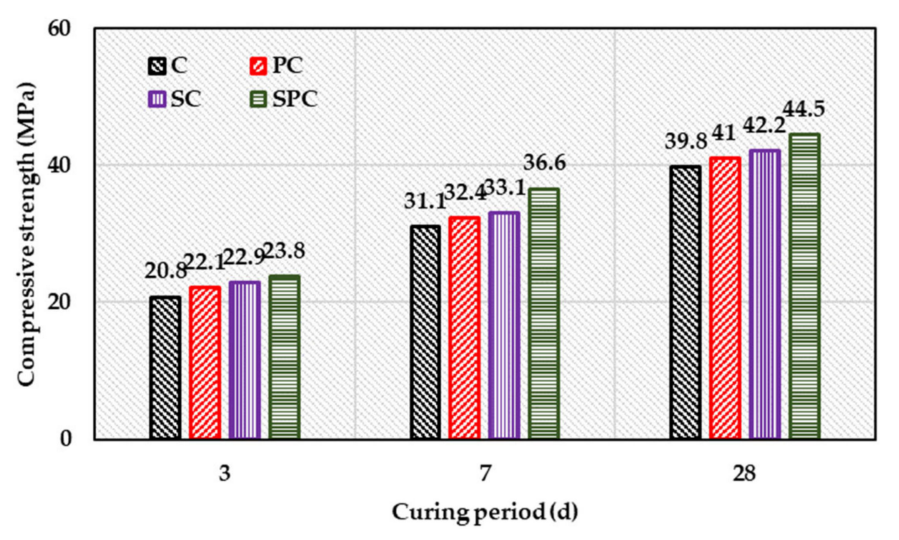

Figure 10. Compressive strength test results of impermeable concrete. 
The failure strain of impermeable concrete samples after a 28-d curing period is shown in Figure 11. It can be seen from Figure 11 that the sequence of failure strain for impermeable concrete is PC $>$ SPC $>$ C $>$ SC, which indicates that the addition of polypropylene fiber is the most significant for improving the flexibility of concrete. This is because PP itself has a certain tensile ability, which acts like tiny steel bars embedded and anchored evenly in the concrete. The PP can improve the flexibility of concrete and reduce the internal stress of concrete and prevent the generation and occurrence of cracks. Since the failure strain of concrete is very small and it can be regarded as an elastic body before failure, the elastic modulus of impermeable concrete samples after a 28-d curing period can be calculated though the ratio of failure stress to strain, as is shown in Figure 11. The elastic modulus of normal concrete is $28,428 \mathrm{~N} / \mathrm{mm}^{2}$, which is consistent with the grade of C30 concrete, which also proves the validity of this measurement. SC has the largest elastic modulus, this indicates that SC is not easy to deform and has the largest rigidity and hardness among the four kinds of concrete. It may be because the active ingredients from the CCCW coating can penetrate into the cement matrix through the carrier of moisture and react with hydration products to form crystalline or gelatinous substances which fill the capillary pores and micro cracks, making the concrete denser, improving the original elastic modulus.

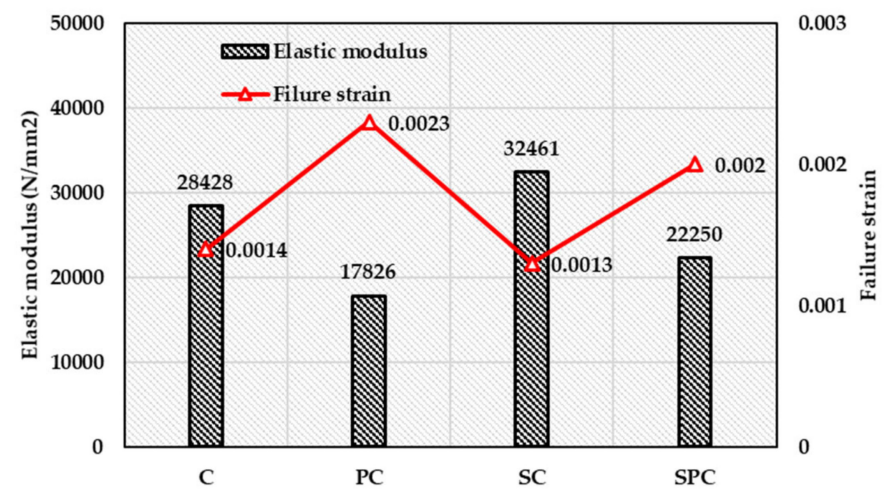

Figure 11. Failure strain and elastic modulus of impermeable concrete after a 28-d curing period.

\subsection{Splitting Tensile Test Results}

The splitting tensile strength of impermeable concrete samples is shown in Figure 12. As shown in Figure 12, for C, PC, SC and SPC, the splitting tensile strength gradually increased with the increase in curing age and the splitting tensile strength of four concretes meet the specifications. When the curing age is 3 days, the splitting tensile strengths of PC, SC, SPC are increased by $17.5 \%, 14.4 \%$ and $29.9 \%$, respectively. When the curing age is 7 days, the splitting tensile strengths of PC, SC, SPC are increased by $18.8 \%, 12.9 \%$ and $30.1 \%$, respectively. When the curing age is 28 days, the splitting tensile strengths of PC, SC, SPC are increased by $18.1 \%, 11.8 \%$ and $24.7 .1 \%$, respectively. The splitting tensile strengths of the three impermeable concretes are higher than that of normal concrete, which also shows that the addition of CCCAM and PP can improve the splitting property of concrete. The addition of PP can fill the voids between concrete aggregates, making the concrete denser, improving the original elastic modulus, and effectively improving the continuity of the internal structure of concrete. Moreover, PP itself has a certain tensile ability, which acts like tiny steel bars embedded and anchored evenly in the concrete. The PP can offset a part of the tensile stress during the process of the splitting tensile test, reducing the internal stress of concrete and preventing the generation and occurrence of cracks, so the splitting tensile strength of PC is greater than that of SC. The splitting tensile strength of SPC is much higher than that of SC and PC, which indicates that the addition of PP and CCCAM at the same time has a better influence on improving the splitting tensile strength than the addition of PP or CCCAM alone. The tension-compression ratio index is the ratio of the splitting tensile strength to compressive strength of concrete, which can be used to evaluate the brittleness of concrete. The smaller the tension-compression ratio of concrete, the stronger the brittleness of concrete and the lower the 
toughness. It can be seen from Figure 12, at the same curing age, that the tension-compression ratios of PC, SC and SPC are improved to different degrees compared with normal concrete, which indicates that the addition of PP or CCCAM can improve the brittleness and enhance the toughness of concrete.

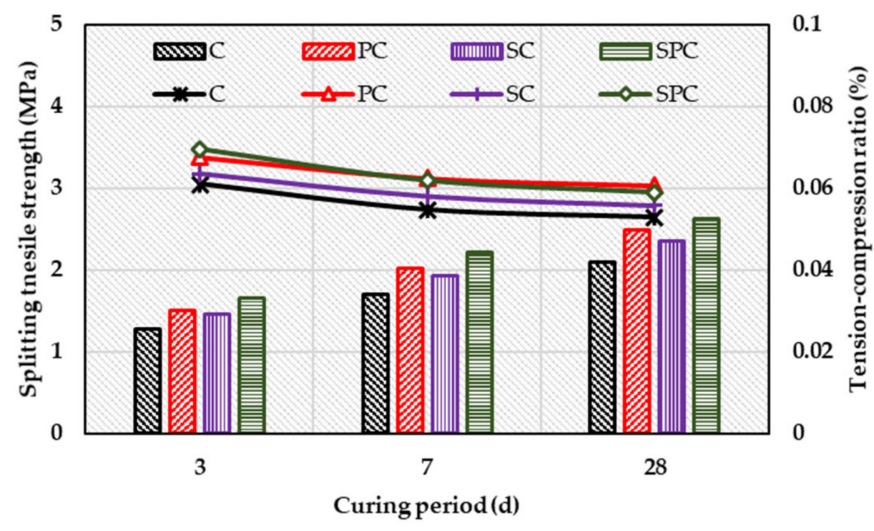

Figure 12. Splitting tensile test results of impermeable concrete.

\subsection{Four-Point Bending Test Results}

The rupture strength of concrete samples is shown in Figure 13 for C, PC, SC and SPC. Under the same curing age, the sequence of rupture strength for the concretes is SPC $>\mathrm{PC}>\mathrm{SC}>\mathrm{C}$, which is consistent with splitting tensile test results. When the curing age is 3 days, the rupture strengths of PC, SC, SPC are increased by $17.5 \%, 14.4 \%$ and $29.9 \%$, respectively, compared with normal concrete. When the curing age is $7 \mathrm{~d}$, the splitting tensile strengths of PC, SC, SPC are increased by $18.8 \%, 12.9 \%$ and $30.1 \%$, respectively. When the curing age is 28 days, the splitting tensile strengths of PC, SC, SPC are increased by $18.1 \%, 11.8 \%$ and $24.7 .1 \%$, respectively. In conclusion, PP improves the rupture strength of concrete better than the CCCAM.

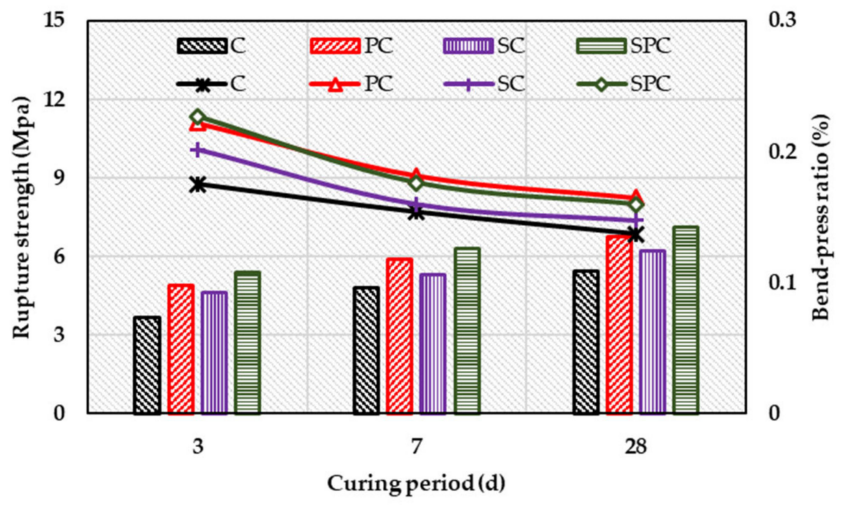

Figure 13. Four-point bending test results of impermeable concrete

The bend-press ratio index is the ratio of rupture strength to compressive strength of concrete. The bend-press ratio can be used to evaluate the brittleness of concrete. The greater the bend-press ratio of concrete, the lower the brittleness of concrete and the stronger the toughness. As shown in Figure 13, at the same curing age, the bend-press ratios of PC, SC and SPC are improved to different degrees compared with normal concrete, which indicates that the addition of PP or CCCAM can improve the brittleness and enhance the toughness of concrete. Among them, PP shows the most significant improvement. It may be because PP can fill the voids between concrete aggregates, making the concrete denser, improving the original elastic modulus, effectively improving the continuity of the internal structure of concrete. Moreover, PP itself has a certain tensile ability, which also can improve the toughness of concrete. It also can be verified from Figure 6, that the sequence of the crack width 
for the concretes is C > SC > SPC > PC after the four-point bending test. In Figure 13, for C, PC, $\mathrm{SC}$ and SPC, the bend-press ratio gradually decreases with the increase in curing age. This is because the growth rate of rupture strength is not as fast as that of compressive strength, with the increase in curing age.

\subsection{Impermeability Test Results}

The impermeability test results of concrete samples are shown in Figure 14. It can be seen from Figure 14 that the average seepage heights of PC, SC and SPC are lower than that of normal concrete, which indicates that the addition of CCCAM and PP can improve the impermeability of concrete. The relative permeability coefficients of PC, SC and SPC are reduced by $52.2 \%, 89.2 \%$ and $79.9 \%$, respectively. From a microscopic point of view, any dense concrete has micro-cracks, and these micro-cracks exist between phases. In the process of hardening and forming strength of concrete, the water and cement can form crystals in the initial stage, and the volume of crystals is smaller than that of raw material, which causes the volume shrinkage of concrete. In the later stage, the dry shrinkage of concrete occurs due to the evaporation of free moisture in the concrete. When these shrinkage stresses exceed the tensile strength of the cement body in a certain period, micro-cracks occur in the concrete. During the setting and hardening process of concrete, the micro-cracks in the concrete will develop into larger cracks, eventually forming through capillary channels and cracks, which lead to the failure of the waterproofing. PP has a large specific area and strong binding force with the cement aggregate, it can form a uniform chaotic support system inside the concrete, that can support the aggregate, effectively inhibit the development of micro-cracks and reduce the bleeding of concrete surface and aggregate segregation. Moreover, the PP can reduce the content of voids with a diameter greater than $50 \mathrm{~mm}$ in concrete, which can greatly improve the impermeability of concrete. The active ingredients from the $\mathrm{CCCW}$ coating can penetrate into the cement matrix through the carrier of moisture and react with hydration products to form crystalline or gelatinous substances which fill the capillary pores and micro cracks. The crystalline substance absorbs moisture and expands in the structural pores, and forms a dense impermeable area gradually from the surface layer to the depth of the concrete structure, which greatly improves the impermeability of the structure. Moreover, the crystalline substance blocks the pore pipes and micro-cracks of the concrete and automatically repairs the small damage of the concrete, thus reducing the porosity of the concrete, and improving the secondary impermeability of the concrete. Among the three impermeability concretes, the impermeability of SC is most significant. The relative permeability coefficient of SC is $9.3 \%$ higher than that of SPC, which indicates that the incorporation of PP does not reduce the impermeability of SC. It may be that PP occupies a certain volume of concrete so that the cement-based osmotic crystallization masterbatch cannot be evenly distributed in the concrete, resulting in the impermeability of SPC being not as good as that of SC.

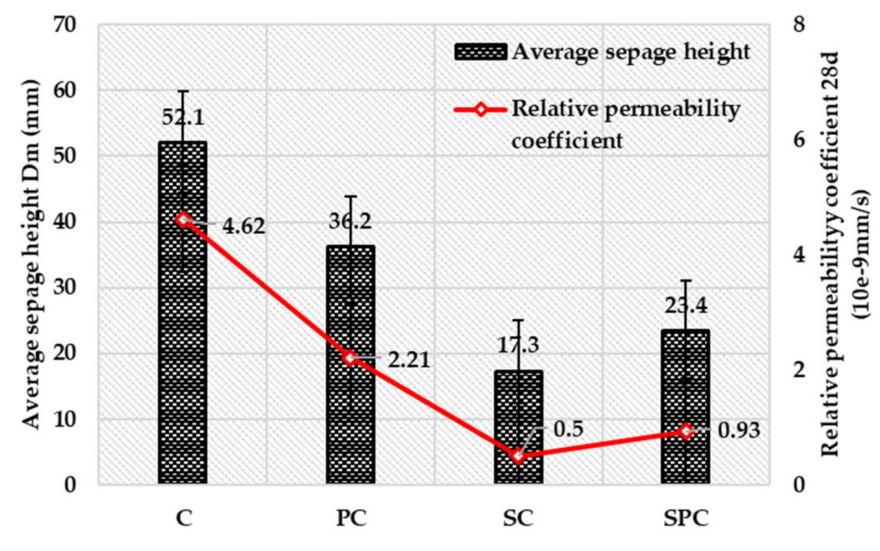

Figure 14. Impermeability test results of impermeable concrete. 


\subsection{Consolidation Performace Test Results of Waterproof Coating}

\subsubsection{Influence Analysis of Waterproof Coating Dosage}

The consolidation strength of the three waterproof coatings with different dosages is shown in Figure 15. It can be seen from Figure 15 that the consolidation strength of the three waterproof coatings first increases and then decreases with the increase in dosage. According to the regression equation, the optimal dosages of SBS, PLT and UPLS are $1.18 \mathrm{~kg} / \mathrm{m}^{2}, 0.95 \mathrm{~kg} / \mathrm{m}^{2}$ and $1.15 \mathrm{~kg} / \mathrm{m}^{2}$, respectively. The following analysis of environmental factors is based on the optimal dosage of the waterproof coating. SBS has the worst consolidation strength between the three waterproof coatings. This is because SBS develops a physical bond, while the other two coatings develop a chemical bond. PLT molecular chains contain -NCO and -NH-COO-, so PLS shows high activity and polarity. PLT can chemically bond with porous materials containing active hydrogen and material with smooth surfaces. The surface tension of steel is very high, and there is generally adsorbed moisture on its surface (even if the metal surface has been polished, there are traces of adsorbed moisture or metal oxide hydrate). -NCO can react with the adsorbed moisture to form a urea bond. The urea bond and metal oxides form metal oxide complexes through hydrogen bonds. Moreover, the -NCO can also form covalent bonds with metal hydrates. As an inorganic material, the surface of concrete also contains adsorbed moisture and hydroxyl, and its bonding mechanism with PLS is roughly the same as that of metal. UPLS is mainly composed of linear unsaturated resin and reactive monomer, both of which contain unsaturated bonds. Under certain conditions (such as heating and UV irradiation, etc.), unsaturated monomer molecules are copolymerized. During the copolymerization process, with the release of heat, the viscosity of the UPLS increases rapidly and finally it becomes a solid that neither dissolves nor melts.

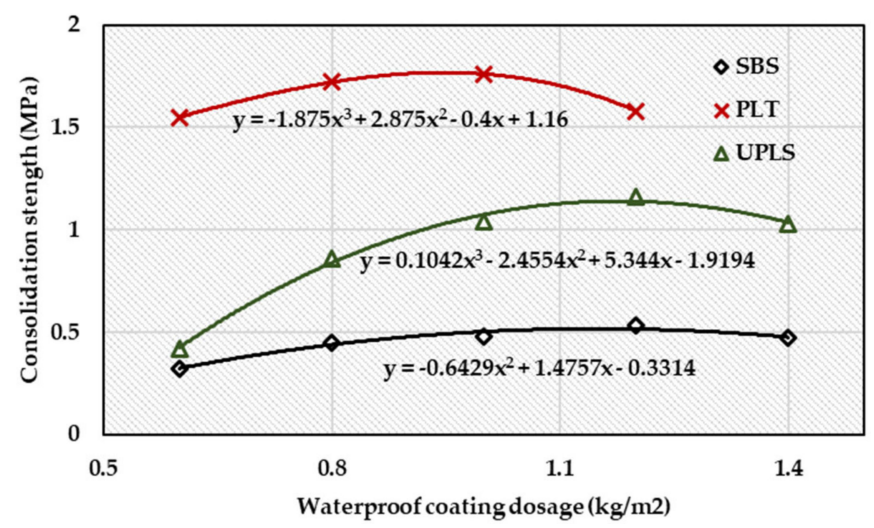

Figure 15. Consolidation strengths of the three waterproof coatings with different dosages.

\subsubsection{Influence Analysis of Temperature}

The consolidation strength of the three waterproof coatings at different temperature is shown in Figure 16. It can be seen from Figure 16 that the consolidation strength of the three waterproof coatings first increases and then decreases with the increase in temperature. The consolidation strengths of the three waterproof coatings reach the maximum at $25^{\circ} \mathrm{C}$, and the maximum consolidation strengths of SBS, PLT and UPLS are 0.52 $\mathrm{MPa}, 1.76 \mathrm{MPa}$ and $1.15 \mathrm{MPa}$, respectively. The consolidation strengths of SBS, PLT and UPLS at $40{ }^{\circ} \mathrm{C}$ decrease by $71.2 \%, 38.6 \%$ and $49.6 \%$, respectively, compared with those at $25{ }^{\circ} \mathrm{C}$. The consolidation strengths of SBS, PLT and UPLS at $60{ }^{\circ} \mathrm{C}$ decrease by $82.7 \%, 59.1 \%$ and $68.7 \%$, respectively, compared with those at $25^{\circ} \mathrm{C}$. In conclusion, when the temperature is above $25^{\circ} \mathrm{C}$, the consolidation strength loss rates of the three waterproof coatings increase with the temperature increase. Among the above three waterproof coatings, PLT has the best consolidation performance, followed by UPLS, and the SBS has the worst consolidation performance at different temperature. This is because SBS, as a modified asphalt, is a material that is more sensitive to temperature, and its 
viscosity and complex shear modulus are greatly affected by temperature. The chemical connection of PLS between concrete and metal is less affected by temperature. This indicates that PLS has excellent rubber properties and can adapt to the adhesion of substrates with different thermal expansion coefficients. It can form a hard-soft-hard transition layer between the substrates, which not only has strong adhesion, but also has excellent cushioning and shock absorption functions.

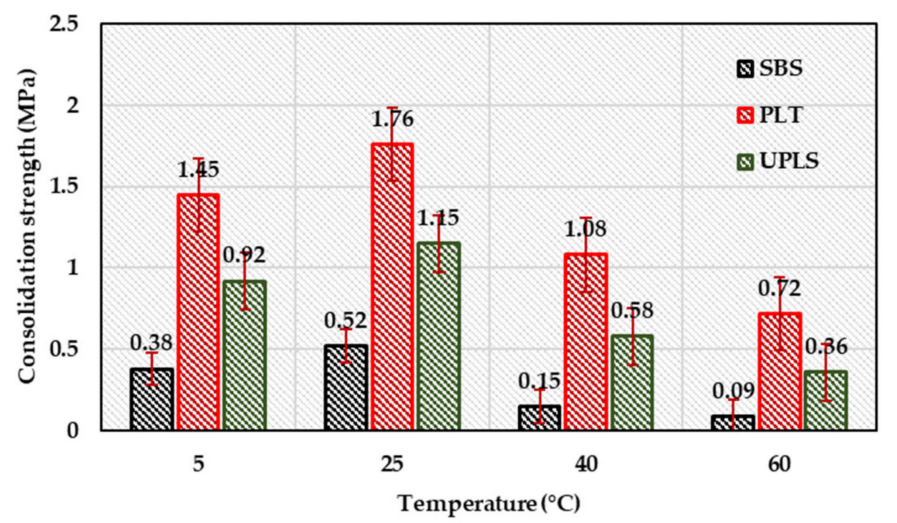

Figure 16. Consolidation strengths of the three waterproof coatings at different temperatures.

\subsubsection{Influence Analysis of Humidity}

The consolidation strengths of the three waterproof coatings at different moistures is shown in Figure 17. It can be seen from Figure 17 that the consolidation strengths of the three waterproof coatings decrease with the increase of humidity. The consolidation strengths of SBS, PLT and UPLS are $0.52 \mathrm{MPa}, 1.76 \mathrm{MPa}$ and $1.15 \mathrm{MPa}$, respectively, at $30 \%$ humidity. The consolidation strengths of SBS, PLT and UPLS at $60 \%$ humidity decrease by $9.6 \%, 4.0 \%$ and $7.8 \%$, respectively, compared with those at $30 \%$ humidity. The consolidation strengths of SBS, PLT and UPLS at $95 \%$ humidity decrease by $38.3 \%, 16.6 \%$ and $19.8 \%$, respectively, compared with those at $60 \%$ humidity. This indicates that the consolidation strength losses of the three waterproof coatings are most significant when the humidity is increased from $60 \%$ to $95 \%$. When the humidity is $95 \%$ to $100 \%$, the consolidation strength losses of the three waterproof coatings is relatively small. According to the consolidation strength test results of the three waterproof coatings, the sensitivity of waterproof coatings to humidity is not as obvious as that to temperature. Among the above three waterproof coatings, PLT has the best consolidation performance, followed by UPLS, and the SBS has the worst consolidation performance at different humidity's. This also indicates that PLT can better bond steel plate and concrete together and has the best waterproof performance at various humidity's.

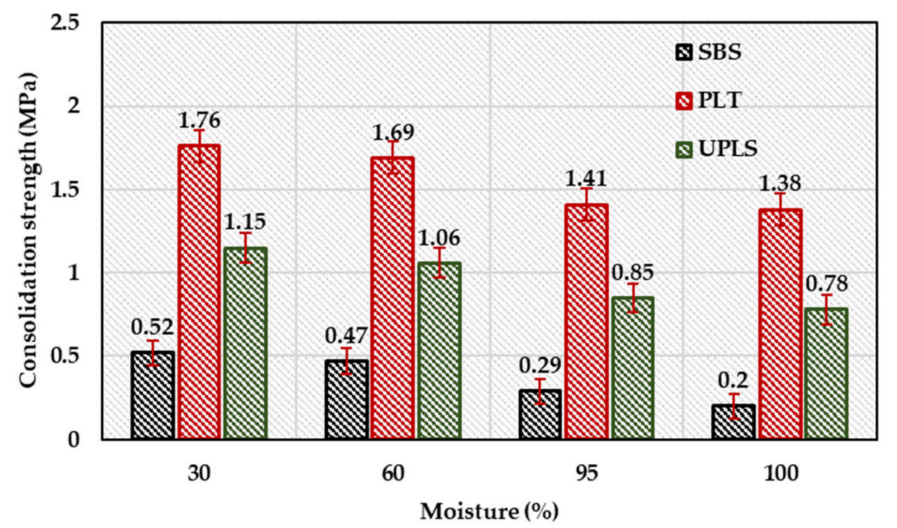

Figure 17. Consolidation strengths of the three waterproof coatings at different moistures. 


\subsubsection{Influence Analysis of Freeze-Thaw Cycles}

The consolidation strength of the three waterproof coatings after a F-T cycle is shown in Figure 18. It can be seen from Figure 18 that F-T cycles have a significant influence on consolidation strengths of the three waterproof coatings. After F-T cycles, the consolidation strengths of SBS, PLT and UPLS decrease by $21.2 \%, 14.2 \%$ and $17.4 \%$, respectively. The consolidation strength of SBS decreases most obviously after F-T cycles. The reason is that SBS modified asphalt is aged after F-T cycles; the SBS modified asphalt becomes hard and brittle, and its adhesive and adhesion performances decrease. The bond formed by UPLS between concrete and steel is like a solid consolidation, while the PLT has more rubber properties and can adapt to the adhesion of substrates with different thermal expansion coefficients. It can form a hard-soft-hard transition layer between the concrete and steel, reduce the temperature stress and the influence of F-T cycles on the consolidation strength of the coating.

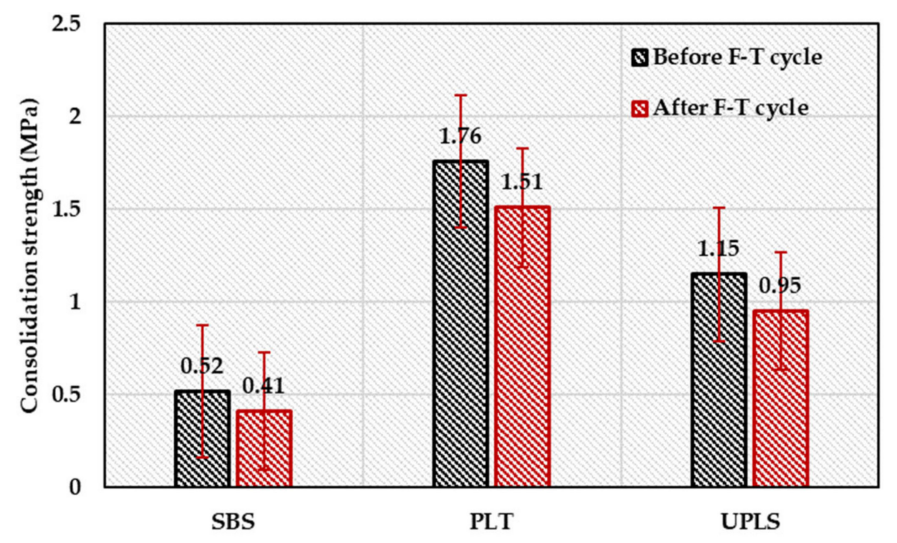

Figure 18. Consolidation strengths of the three waterproof coatings after F-T cycles.

In conclusion, the compressive strength, splitting tensile strength, rupture strengths of concrete mixed with polypropylene fiber and cementitious capillary crystalline waterproofing material were increased by $11.8 \%, 24.7 \%$ and $30.4 \%$, respectively, compared with normal concrete. The relative permeability coefficient of SPC was reduced by $79.9 \%$ compared with normal concrete. Compared with the commonly used cementitious capillary crystalline waterproofing material, the compressive strength, splitting tensile strength, rupture strength of SPC were increased by $5.5 \%, 11.5 \%$ and $14.3 \%$, respectively. The relative permeability coefficients of SPC and concrete mixed with cementitious capillary crystalline waterproofing material were $0.93 \mathrm{e}-9 \mathrm{~mm} / \mathrm{s}$ and $0.5 \mathrm{e}-9 \mathrm{~mm} / \mathrm{s}$, which meet the impermeability requirements. This indicates that SPC not only meets the impermeability requirements, but also has excellent mechanical properties. Compared with the commonly used SBS waterproof coating, the amount of PLS used as waterproof coating is lower. Moreover, the consolidation strength of PLS waterproof coating is less affected by temperature, humidity and F-T cycles. At the three conditions of $60{ }^{\circ} \mathrm{C}, 100 \%$ humidity and F-T cycles, the consolidation strength of PLS is increased by $700 \%, 590 \%$ and $268 \%$, respectively, compared with SBS waterproof coatings. This indicates that the PLS waterproof coating not only has a high consolidation strength to effectively prevent the infiltration of moisture, but also maintains excellent properties in a complex environment.

\section{Conclusions}

In this paper, spherical hinge moisture damage prevention is investigated comprehensively from two aspects of impermeable concrete and steel-concrete interface waterproof coating. Three impermeable concretes were prepared and tested by the compressive strength test, splitting tensile test, four-point bending test and impermeability test. Moreover, a waterproof coating consolidation performance test was proposed to quantify the interface bond strength of waterproof coatings and determine the optimal dosage of waterproof coatings. Then, the effect of temperature, moisture and 
freeze-thawing cycles on the consolidation performance of waterproof coatings was discussed to judge the waterproof coating with the best performance. The main conclusion are as follows.

1. The mechanical property test results of the three impermeable concretes illustrated that addition of CCCAM and PP could improve the toughness and brittleness of concrete. The compressive strength, splitting tensile strength, rupture strengths of SPC were increased by $11.8 \%, 24.7 \%$ and $30.4 \%$, respectively, compared with normal concrete.

2. The impermeability test results showed that the addition of CCCAM was an effective technique for improving the permeability of concrete. The relative permeability coefficient of concrete supplemented with CCCAM is reduced by $89.2 \%$ compared with normal concrete. Moreover, the incorporation of PP and CCCAM at the same time cannot improve the impermeability of concrete. This may be because the chaotic support structure formed by PP prevents the infiltration and uniform dispersion of CCCAM

3. The consolidation performance test showed that temperature had a significant effect on the interface consolidation property of waterproof coatings. Moreover, the optimal dosages of SBS, PLT and UPLS waterproof coating are $1.18 \mathrm{~kg} / \mathrm{m}^{2}, 0.95 \mathrm{~kg} / \mathrm{m}^{2}$ and $1.15 \mathrm{~kg} / \mathrm{m}^{2}$, respectively.

4. From the consolidation performance test, it was understood that PLS waterproof coating maintained excellent properties in a complex environment. This is because PLS has excellent shear strength, impact resistance, flexibility and rubber characteristics, and it can form a hard-soft-hard transition layer between the concrete and steel, reduce the impact of environmental factors.

Author Contributions: Conceptualization, X.G. and Z.W.; Data curation, W.G.; Funding acquisition, X.G. and Z.W.; Investigation, W.G.; Methodology, Z.L.; Project administration, X.G. and Z.L.; Writing-original draft, W.G. and Z.W.; Writing-review and editing, X.G. and Z.L. All authors have read and agreed to the published version of the manuscript.

Funding: This research was funded by the National Nature Science Foundation of China (NSFC) (Grant No. 51178204), Jilin Province Science and Technology Development Plan Project (Grant No. 20190303033SF) and China Railway Shenyang Group Co., Ltd. (Grant No. 20190108).

Conflicts of Interest: The authors declare no conflict of interest.

\section{Appendix A}

Table A1. Technical parameters of 'P.O42.5R' Ordinary Portland cement.

\begin{tabular}{ccccccccc}
\hline \multirow{2}{*}{$\begin{array}{c}\text { Technical } \\
\text { Parameters }\end{array}$} & \multirow{2}{*}{ Density } & \multirow{2}{*}{$\begin{array}{c}\text { Specific Surface } \\
\text { Area }\end{array}$} & \multicolumn{2}{c}{ Setting Time } & \multicolumn{2}{c}{ Compressive Strength } & \multicolumn{2}{c}{ Flexural Strength } \\
\cline { 4 - 8 } & & & Initial Set & Final Set & $3 \mathrm{~d}$ & $28 \mathrm{~d}$ & $3 \mathrm{~d}$ & $28 \mathrm{~d}$ \\
\hline Units & $\mathrm{kg} / \mathrm{m}^{3}$ & $\mathrm{~m}^{3} / \mathrm{kg}$ & $\min$ & $\min$ & $\mathrm{MPa}$ & $\mathrm{MPa}$ & $\mathrm{MPa}$ & $\mathrm{MPa}$ \\
Value & 3100 & 358 & 195 & 290 & 13.9 & 48.9 & 7.7 & 8.1 \\
\hline
\end{tabular}

Table A2. Technical parameters of coarse aggregates.

\begin{tabular}{ccccc}
\hline $\begin{array}{c}\text { Technical } \\
\text { Parameters }\end{array}$ & Crushing Value & $\begin{array}{c}\text { Los Angeles } \\
\text { Attrition Rate }\end{array}$ & Mud Content & Clay Lump \\
\hline Units & $\%$ & $\%$ & $\mathrm{~g} / \mathrm{cm}^{3}$ & $\%$ \\
Measured value & 21.2 & 25 & 2.7 & 9.3 \\
Standard value & $\leq 26$ & $\leq 28$ & $\geq 2.6$ & $\leq 15$ \\
\hline
\end{tabular}

Table A3. Technical parameters of sand.

\begin{tabular}{ccccc}
\hline $\begin{array}{c}\text { Technical } \\
\text { Parameters }\end{array}$ & Apparent Density & Bulk Density & Mud Content & Clay Lump \\
\hline Units & $\mathrm{kg} / \mathrm{m}^{3}$ & $\mathrm{~kg} / \mathrm{m}^{3}$ & $\%$ & $\%$ \\
Measured value & 2700 & 1540 & 1.6 & 0.6 \\
Standard value & $\geq 2500$ & $\geq 1400$ & $\leq 3.0$ & $\leq 1.0$ \\
\hline
\end{tabular}


Table A4. Technical parameters of fly ash.

\begin{tabular}{|c|c|c|c|c|c|c|c|}
\hline $\begin{array}{c}\text { Technical } \\
\text { Parameters }\end{array}$ & Appearance & Density & $\begin{array}{c}\text { Water } \\
\text { Content }\end{array}$ & Fineness & $\begin{array}{l}\text { Loss on } \\
\text { Ignition }\end{array}$ & $\begin{array}{c}\mathrm{SO}_{2} \\
\text { Content }\end{array}$ & Water Demand Ratio \\
\hline Units & N/A & $\mathrm{g} / \mathrm{cm}^{3}$ & $\%$ & $\%$ & $\%$ & $\%$ & $\%$ \\
\hline Measured value & Cement color power & 2.4 & 0.5 & 11.3 & 3.01 & 0.27 & 93 \\
\hline
\end{tabular}

Table A5. Technical parameters of DMC-S-WS-710B cementitious capillary crystalline active masterbatch (CCCAM).

\begin{tabular}{cccccccccc}
\hline \multirow{2}{*}{ Technical Parameters } & \multirow{2}{*}{ Appearance } & \multirow{2}{*}{ Particle Size } & \multicolumn{2}{c}{ Setting Time Difference } & Penetration Height & \multicolumn{2}{c}{ Compressive Strength } \\
& & & Initial Set & Final Set & & Ratio & & $7 \mathrm{~d}$ & $28 \mathrm{~d}$ \\
\hline Units & N/A & $\mu \mathrm{m}$ & $\min$ & $\min$ & $\%$ & $\%$ & $\%$ \\
Value & $\begin{array}{c}\text { Grey } \\
\text { powder }\end{array}$ & $45-150$ & & $-90-+120$ & $-120-+120$ & $\leq 40$ & $\geq 100$ & $\geq 95$ \\
\hline
\end{tabular}

Table A6. Technical parameters of polypropylene fiber.

\begin{tabular}{ccccccc}
\hline $\begin{array}{c}\text { Technical } \\
\text { Parameters }\end{array}$ & Diameter & Length & Density & $\begin{array}{c}\text { Elastic } \\
\text { Modulus }\end{array}$ & $\begin{array}{c}\text { Breaking } \\
\text { Strength }\end{array}$ & $\begin{array}{c}\text { Breaking } \\
\text { Elongation }\end{array}$ \\
\hline Units & $\mu \mathrm{m}$ & $\mathrm{mm}$ & $\mathrm{g} / \mathrm{cm}^{3}$ & $\mathrm{GPa}$ & $\mathrm{MPa}$ & $\%$ \\
Value & 26 & $8-12$ & 1.3 & 36 & 1280 & 5 \\
\hline
\end{tabular}

Table A7. Technical parameters of Styrene-Butadiene-Styrene modified asphalt.

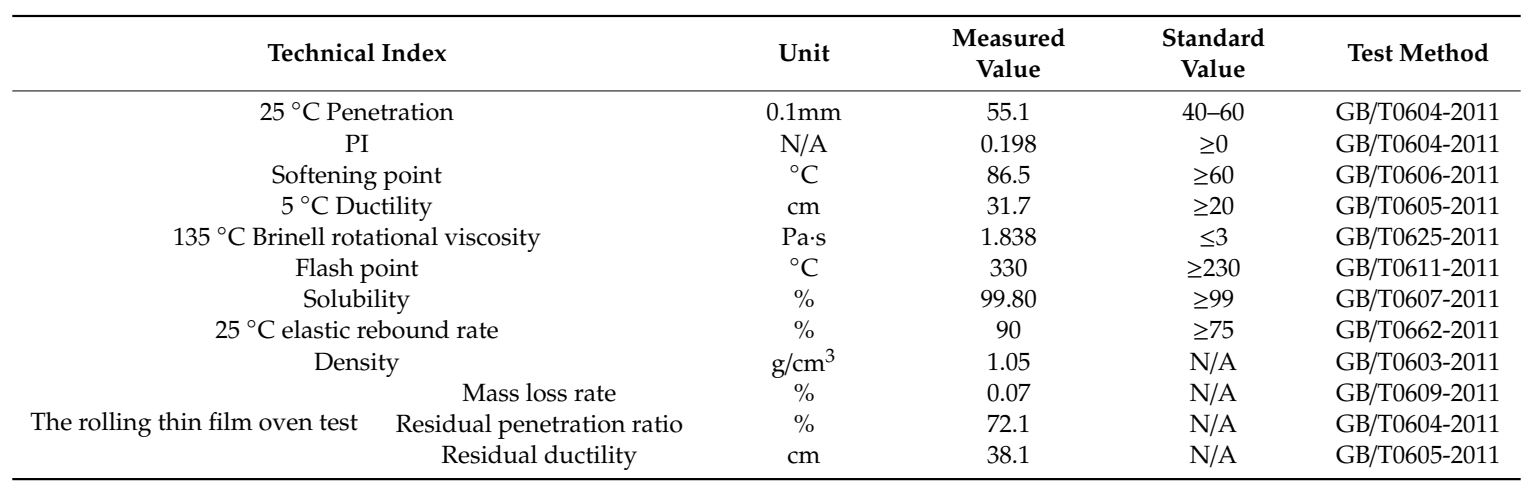

Table A8. Technical parameters of polyurethane.

\begin{tabular}{cccc}
\hline Technical Index & Unit & Measured Value & Standard Value \\
Appearance & $\mathrm{N} / \mathrm{A}$ & Uniform viscous body, no gel or & $\begin{array}{c}\text { Uniform viscous body, no gel or } \\
\text { lumps }\end{array}$ \\
Solid content & $\%$ & 89.8 & $\geq 85.0$ \\
Surface drying time & $\mathrm{h}$ & 6 & $\leq 12$ \\
Hard drying time & $\mathrm{h}$ & 11 & $\leq 24$ \\
Tensile strength & $\mathrm{MPa}$ & 2.51 & $\geq 2.00$ \\
Breaking elongation & $\%$ & 607 & $\geq 500$ \\
Tear strength & $\mathrm{N} / \mathrm{mm}$ & 18 & $\geq 15$ \\
Permeability & $\mathrm{N} / \mathrm{A}$ & No cracks $\left(-35^{\circ} \mathrm{C}\right)$ & No cracks \\
Low temperature bending resistance & $\mathrm{N} / \mathrm{A}$ & Impermeable $(0.3 \mathrm{MPa}, 120 \mathrm{~min})$ & -2.2 \\
Heating expansion rate & $\%$ & 1.2 & $-4.0-+1.0$ \\
Bonding strength & $\mathrm{MPa}$ & 3.0 & $\geq 1.0$ \\
Water absorption & $\%$ & & $\leq 5.0$ \\
\hline
\end{tabular}


Table A9. Technical parameters of 99A high transparent crystal resin.

\begin{tabular}{cccc}
\hline Technical Index & Unit & Measured Value & Standard Value \\
\hline Appearance & $\mathrm{N} / \mathrm{A}$ & Colorless transparent liquid & N/A \\
Chroma (Pt-C0) & $\mathrm{N} / \mathrm{A}$ & $25-35$ & $\mathrm{~GB} / \mathrm{T} 7193.7-2008$ \\
Acid value & $\mathrm{mgKOH} / \mathrm{g}$ & $15-25$ & $\mathrm{~GB} / \mathrm{T} 2895-2008$ \\
Solid content & $\%$ & $60-80$ & $\mathrm{~GB} / \mathrm{T} 7193.3-2008$ \\
$25^{\circ} \mathrm{C}$ viscosity & $\mathrm{mPa} \cdot \mathrm{s}$ & $350-600$ & $\mathrm{~GB} / \mathrm{T} 7193.1-2008$ \\
Solidification time & $\mathrm{min}$ & $20-30$ & $\mathrm{~GB} / \mathrm{T} 7193.6-2008$ \\
$80^{\circ} \mathrm{C}$ stability & $\mathrm{h}$ & $\geq 24$ & $\mathrm{~GB} / \mathrm{T} 7193.5-2008$ \\
\hline
\end{tabular}

Table A10. Technical parameters of resin casting body.

\begin{tabular}{cccc}
\hline Technical Index & Unit & Measured Value & Standard Value \\
\hline Appearance & $\mathrm{N} / \mathrm{A}$ & No defects & N/A \\
Tensile strength & $\mathrm{MPa}$ & 67 & $\mathrm{~GB} / \mathrm{T} 2568-2008$ \\
Tensile elastic modulus & $\mathrm{MPa}$ & 3500 & $\mathrm{~GB} / \mathrm{T} 2568-2008$ \\
Breaking elongation & $\%$ & 2.50 & $\mathrm{~GB} / \mathrm{T} 2568-2008$ \\
Bending strength & $\mathrm{MPa}$ & 100 & $\mathrm{~GB} / \mathrm{T} 2570-2008$ \\
Flexural modulus & $\mathrm{MPa}$ & 3700 & $\mathrm{~GB} / \mathrm{T} 2570-2008$ \\
Impact toughness & $\mathrm{KJ} / \mathrm{m}^{2}$ & 10.0 & $\mathrm{~GB} / \mathrm{T} 2571-2008$ \\
Thermal distortion temperature & ${ }^{\circ} \mathrm{C}$ & 65 & $\mathrm{~GB} / \mathrm{T}$ 1634-2008 \\
Barcol hardness & Barcol & 45 & GB/T 3854-2008 \\
\hline
\end{tabular}

\section{References}

1. Guo, Z.H.; Zhang, Z. Erection of pearl bridge by bear angle vertical swivel method. Adv. Mater. Res. 2010, 163, 1-7. [CrossRef]

2. Zhou, Z.X.; Li, F.; Imbsen, R. Vertical erection-rotation method for chorded arch bridge. Struct. Eng. Int. 2009, 19, 142-148. [CrossRef]

3. Li, W.W.; Zhang, Z.; Huang, C.L. Application of dynamic unstressed state method in vertical rotation construction of bridges. Adv. Mater. Res. 2011, 255, 988-992. [CrossRef]

4. Wang, S.J.; Zhou, X. Application of CAD and finite element method in the gravity center analysis of body rotating cable-stayed bridge. Adv. Mater. Res. 2011, 243, 1549-1552. [CrossRef]

5. Che, X.; Zhang, X. Overturning resistance of large tonnage T-shaped rigid frame bridge during turning. J. China Highw. 2014, 27, 66-72.

6. Du, J. Innovation and prospect of bridge rotation construction technology. J. Railw. Constr. Technol. 2012, 4, 7-11.

7. Gharpure, D.R.; Biyani, S.R. Poira bridge: Construction of India's first horizontal swing bridge. Indian Concr. J. 2007, 81, 33-35.

8. Siwowski, T.; Wysocki, A. Horizontal rotation via floatation as an accelerated bridge construction for long-span footbridge erection: Case study. J. Bridge. Eng. 2014, 20, 05014014. [CrossRef]

9. Hu, J.; Sun, X.Y.; Jiao, S.J. Monitoring of long-span self-anchored arch bridge constructed with rotation method. Appl. Mech. Mater. 2012, 178, 1977-1982. [CrossRef]

10. Feng, Y.; Qi, J.N.; Wang, J.Q. Rotation construction of heavy swivel arch bridge for high-speed railway. Structures 2020, 26, 755-764. [CrossRef]

11. Sun, Q.S.; Guo, X.G.; Zhang, D.P. Research on the application of horizontal rotation construction method with flat hinge in cable-stayed bridge construction. Adv. Mater. Res. 2011, 255, 856-860. [CrossRef]

12. Gao, R.; Hu, Z.; Gao, T.M. Analysis of influence of train-induced vibration on the stability of swivel construction bridge. Railway Constr. 2014, 5, 16-18.

13. Xiao, J.; Liu, M.; Zhong, T.; Fu, G. Seismic performance analysis of concrete-filled steel tubular single pylon cable-stayed bridge with swivel construction. IOP. Conf. Ser. Earth Environ. Sci. 2019, 218, 012087. [CrossRef]

14. Almusallam, A.A.; Khan, F.M.; Dulajan, S.U.; Al-Amoudi, O.S.B. Effectiveness of surface coatings in improving concrete durability. Cem. Concr. Compos. 2003, 25, 473-481. [CrossRef] 
15. Zhao, Z.G.; Qu, X.L.; Li, J.H. Application of polymer modified cementitious coatings (PCCs) for impermeability enhancement of concrete. Constr. Build. Mater. 2020, 249, 118769. [CrossRef]

16. Huang, B.C.; Wu, H.; Shu, X.; Burdette, E.G. Laboratory evaluation of permeability and strength of polymer-modified pervious concrete. Constr. Build. Mater. 2010, 24, 818-823. [CrossRef]

17. Liu, B.J.; Shi, J.K.; Sun, M.H.; He, Z.; Xu, H.; Tan, J. Mechanical and permeability properties of polymer-modified concrete using hydrophobic agent. J. Build. Eng. 2020, 31, 101337. [CrossRef]

18. Zhang, S.P.; He, P.L.; Niu, L.L. Mechanical properties and permeability of fiber-reinforced concrete with recycled aggregate made from waste clay brick. J. Cleaner Prod. 2020, 268, 121690. [CrossRef]

19. Guo, Y.H.; Zhang, P.Y.; Ding, H.Y. Experimental study on the permeability of SAP modified concrete. Materials 2020, 13, 3368. [CrossRef]

20. Liu, M.M.; Han, S.; Pan, J.; Ren, W. Study on cohesion performance of waterborne epoxy resin emulsified asphalt as interlayer materials. Constr. Build. Mater. 2018, 177, 72-82. [CrossRef]

21. Rhee, J.; Kim, H.; Ock, C. An investigation of the deterioration characteristics of concrete bridge decks with asphalt concrete in Korea. KSCE J. Civ. Eng. 2018, 22, 613-621. [CrossRef]

22. Zhang, Y.T.; Zuo, L.; Yang, J.C.; Cai, X.N.; Zhao, Y.; Zeng, X. Effect of cementitious capillary crystalline waterproofing coating on the gas permeability of mortar. Struct. Concr. 2019, 20, 1763-1770. [CrossRef]

23. Al-Kheetan, M.J.; Rahman, M.M.; Chamberlain, D.A. A novel approach of introducing crystalline protection material and curing agent in fresh concrete for enhancing hydrophobicity. Constr. Build. Mater. 2018, 160, 644-652. [CrossRef]

24. Al-Kheetan, M.J.; Rahman, M.M.; Chamberlain, D.A. Remediation and protection of masonry structures with crystallising moisture blocking treatment. Int. J. Build. Pathol. Adapt. 2018, 36, 77-92. [CrossRef]

25. Karpov, A.I. Theses in the area of nanotechnologies and nanomaterials: Novelties and practical application. Part 2. Nanotechnol. Constr. Sci. Int. J. 2016, 8, 82-103. [CrossRef]

26. Shen, D.J.; Wen, C.Y.; Zhu, P.F.; Wu, Y.; Yuan, J. Influence of Barchip fiber on early-age autogenous shrinkage of high strength concrete. Constr. Build. Mater. 2020, 256, 119223. [CrossRef]

27. Ahmed, T.W.; Ali, A.A.M.; Zidan, R.S. Properties of high strength polypropylene fiber concrete containing recycled aggregate. Constr. Build. Mater. 2020, 241, 118010. [CrossRef]

28. Chen, J.; Ma, X.; Wang, H.; Xie, P.; Huang, W. Experimental study on anti-icing and deicing performance of polyurethane concrete as road surface layer. Constr. Build. Mater. 2018, 161, 598-605. [CrossRef]

29. Marukha, V.I.; Serednyts'kyi, Y.A. Specific features of injection hardening of cracked concrete structures and buildings with polyurethanes. Mater. Sci. 2008, 44, 720-725. [CrossRef]

30. Zeng, L.M.; Wang, S.P. Mechanism and effectiveness of reduction action of unsaturated polyester resin reducer. J. Wuhan Univ. Technol. Mater. Sci. Ed. 2001, 16, 70-74.

31. Penczek, P.; Boncza-Tomaszewski, Z. Unsaturated polyester resins on the verge of the 21st century. Polimery 1999, 44, 709-715. [CrossRef]

(C) 2020 by the authors. Licensee MDPI, Basel, Switzerland. This article is an open access article distributed under the terms and conditions of the Creative Commons Attribution (CC BY) license (http://creativecommons.org/licenses/by/4.0/). 